\title{
Cordaites Felicis, sp. nov., a Cordaitean Leaf from the Lower Coal Measures of England.
}

\author{
BY \\ MARGARET BENSON, D.Sc., F.L.S. \\ Royal Holloway College, University of London. \\ With Plate XXII and one Figure in the Text. \\ CONTENTS.

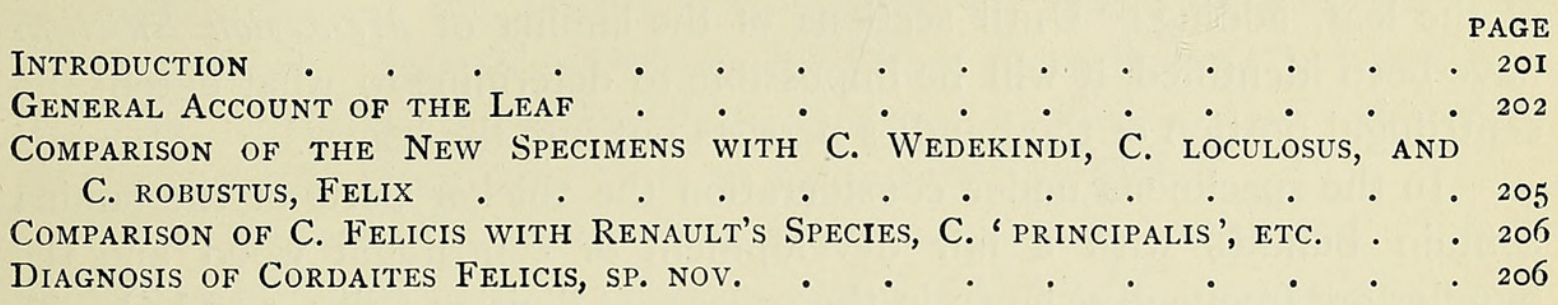

\section{INTRODUCTION.}

$\mathrm{T}^{\mathrm{T}}$ is not uncommon to meet with Cordaitean leaves in the petrified 1 material from British Coal Measures. As a rule, however, the fragments are badly preserved, and beyond the fact that some of them bore a general resemblance to Cordaites Wedekindi, Felix, ${ }^{1}$ little has been observed about them.

In two blocks recently presented to me by Mr. Sutcliffe from his mine at Shore, Littleborough, specimens have been met with which are better preserved, and were therefore photographed. A few of these photographs have been reproduced on Pl. XXII, and a camera drawing of a single bundle is reproduced as a text-figure.

Although these new specimens bear a somewhat close resemblance, as above said, to $C$. Wedekindi, other sections more closely resemble the other two forms described by Prof. Felix under the names of $C$. loculosus and $C$. robustus. For this reason, and because a closer comparison revealed constant minor differences from all three forms, it has seemed necessary to refer to the new specimens under a different specific name.

The name Cordaites Felicis has been selected because of the much closer affinity they show to Prof. Felix's forms than to any of the French forms.

1 Felix : Steinkohlen-Pflanzen. Preuss. Geol. Special-Karte (Abhandlungen), Bd. vii, I885-7

[A,nnals of Botany, Vol, XXVI. No. CI. January, 1919.] 
All the micrographs on PI. XXII (except Fig. 1I) are taken from specimens in a single series from the same boulder. The expense of the work has been in part defrayed by a contribution from the Royal Society Government Grant Committee.

\section{General Account of the Leaf.}

As may be seen by reference to the micrographs, the specimens exhibit a considerable range of structure, but there seems to be no ground for supposing that more than one species is represented. In the leaves of some recent Conifers, as was shown by Seward and Ford in their monograph on the Araucarieae, ${ }^{1}$ the leaf bundles may be diploxylic near the apex, but show no centripetal xylem at the base. Maslen also points out ${ }^{2}$ that the absence of centrifugal primary wood in the specimens described by Dr. M. C. Stopes ${ }^{3}$ may be due to their having come from distal parts of the leaf, adding: 'Until sections of the lamina of Mesoxylon Sutcliffi have been identified, it will be impossible to determine to what extent the centrifugal portion of the bundles persists out into the leaves.'

In the specimens under consideration the thicker parts of the lamina contain bundles with a fair development of centrifugal wood and the bundles are frequently shown in the process of division (Figs. 5 and 6).

In thinner parts of the lamina (i. e. presumably more distal or more peripheral), the centrifugal elements become smaller, are relatively few in number, and in some cases are absent altogether. ${ }^{4}$

The distribution of the sclerenchyma is different in the thicker from that in the thinner parts of the lamina. In the former there is an almost, if not quite, continuous hypodermal layer beneath each surface. In the thinner parts of the leaf the hypodermal layer is interrupted, but both regions of the leaf show supporting plates vertical to the surfaces of the leaf. These plates form complete partitions running the length of the leaf between the bundles and alternating with them (Fig. 3).

They appear in transverse section like columns, and are the more interesting as they do not occur in any of the forms described by Grand'Eury or Renault. They are well represented, on the other hand, in the forms described by Felix, e.g. C. Wedekindi, C. loculosus, and C. robustus. As in most Cordaitean leaves so far described, the vascular bundle is surrounded by a sheath attached to both surfaces by thickening in

1 Seward and Ford: The Araucarieae, Recent and Extinct. Phil. Trans. Royal Soc., B., vol. cxcviii, I906, p. 370 .

2 Maslen: The Structure of Mesoxylon Sutcliffii (Scott). Annals of Botany, vol. xxv, I91 I, p. 406 .

3 Stopes: On the Leaf Structure of Cordaites. New Phytologist, vol. ii, I903.

${ }^{4}$ It seems open to question whether this statement is strictly justifiable, as the inner sheath, which appears to represent the centrifugal xylem, is generally present even when the more central elements are undifferentiated (vide Figs. 8 and 10). 
the hypoderm. In C. Felicis there are also thickened masses of hypoderm between the bundle strand and the partitions (Fig. I0). On the upper surface these masses are surrounded by but slightly differentiated palisade, while on the lower they are surrounded by the lacunar tissue connected with the stomatiferous epidermis.

The horizontal section shown in Fig. 3 is equidistant between the upper and lower surfaces of the leaf and thus escapes the hypodermal masses. The vascular bundles with their well-developed sheaths are approximately circular in section (Fig. IO), and relatively to the thickness of the leaf are larger than those of $C$. Wedekindi, Felix. In the parts of the leaf where division is most frequent, the bundle sheath is scarcely differentiated (Fig. 5). Correlated with the absence of the sheath the partition is more strongly constructed (Figs. 2 and 5), and the specimen approximates to the $C$. robustus type of Felix.

When present the sheath is composed of layers of longitudinally disposed fibres. In some cases pits are shown on their walls, but as a rule the later deposited thickening layers of the wall are dissolved before petrifaction, and the pits are then no longer distinguishable.

The innermost layer of the sheath is generally composed of cells of narrow calibre, and so the abaxial region of the bundle is partially composed of cells like those of the centrifugal primary xylem, which they slightly exceed in size. This sheath may be present even when no normal centrifugal elements may be differentiated (Fig. 8, Is).

To turn to the vascular elements proper, we note that the upper part of the xylem consists of a few large, porose, centripetal tracheides which increase in number as the leaf thickens. A considerable number may be present in the basal part of the leaf, especially when the bundle is dividing (Fig. 6). In the non-dividing bundle the centripetal wood radiates off from a small protoxylem group, which in turn is often separated from the centrifugal elements by a layer of parenchyma. In transverse sections the centrifugal elements, which are small and spiro-reticulate, lie in an irregular crescent which reaches to the periphery of the centripetal wood above and the small-celled inner sheath laterally. Thus, if we regard the tracheides of the inner sheath as primary transfusion tissue derived from xylem, there seems more reason to connect it with the centrifugal xylem than with the centripetal. It will be observed from the text-figure that the tracheides of the inner sheath $(I s)$ are of slightly wider calibre than those intervening between them and the protoxylem $(P x)$.

It is possibly the increasing development of this inner sheath in later forms that explains the more common absence of centrifugal wood in C. principalis as described by Dr. Marie C. Stopes. Below the centrifugal elements is a layer of xylem parenchyma which again is succeeded by the phloem (text-figure, $P$ ). 
The specimens which are here regarded as representing the thicker parts of the leaf of $C$. Felicis correspond in structure much more closely to the forms called $C$. robustus and C. loculosus by Felix. That such forms represent the non-assimilating part of the leaf seems obvious from their structure, as there is no apparatus for gaseous exchange with the external atmosphere. Moreover, they occur with sections possessing a stomatiferous surface, ${ }^{1}$ and all grades of intermediate structure occur. The treatment of such forms by Felix as different species has rendered it necessary to apply a new specific term to the new type, as it is impossible to identify it with any one by itself of the three forms described by Felix. Otherwise it might

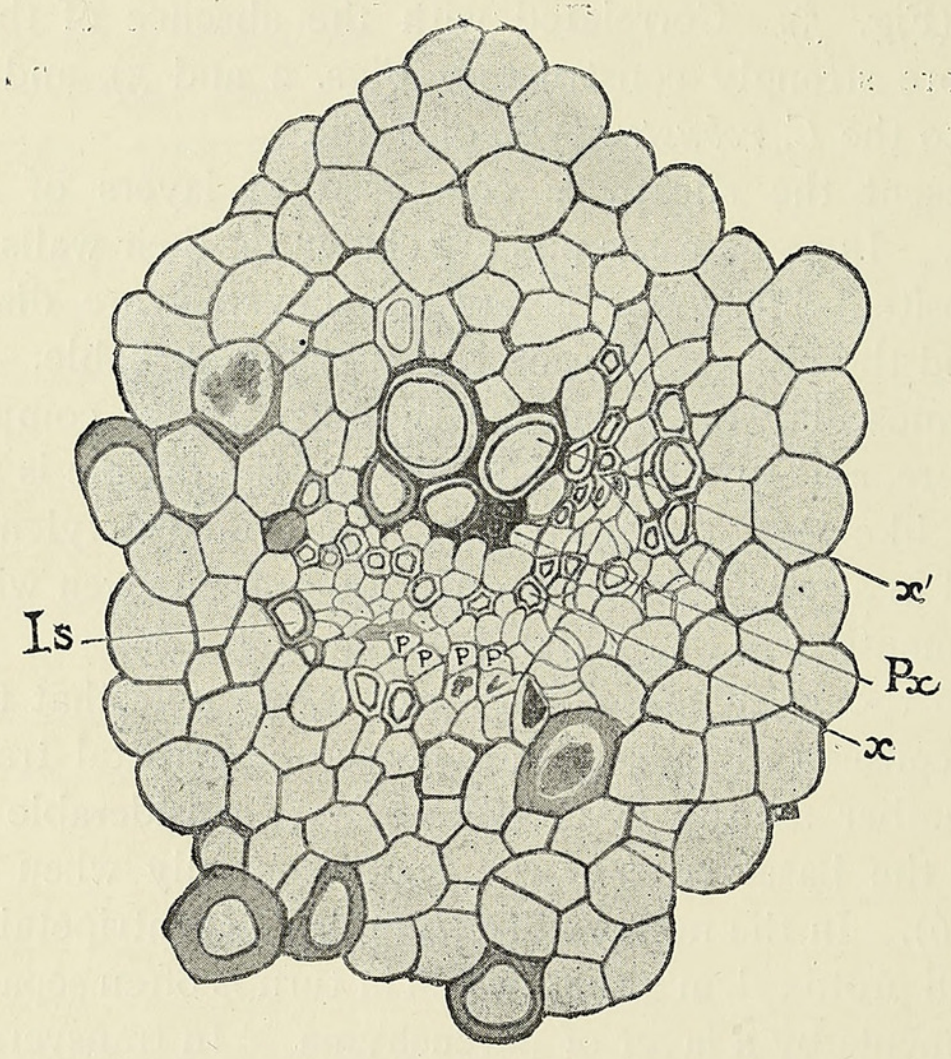

Text-FIG. Transverse section of a single bundle surrounded by its sheath. $\mathbf{x} 225$. The centripetal wood $\left(x^{\prime}\right)$ is in marked contrast with the centrifugal $(x)$. The protoxylem $(P x)$ is separated by a single layer of parenchyma from the centrifugal wood. The elements of the centrifugal wood which contribute to the inner sheath $(I S)$ are larger than the intervening elements. The inner sheath is limited to the abaxial part of the bundle, but the outer sheath is well developed all round the bundle. Some of the phloem elements are indicated by the letter $P$. Shore, C. N., 72. I.

have been best to avoid introducing a new specific term on differences which do not amount to much more than that of size and robustness of development (vide next section).

${ }^{1}$ Felix: loc. cit., p. 62. 'Other leaves of this species, i. e. C. Wedekindi, occur in the section from the Kgl. geol. Landesanstalt, No. I09.' It was in this section that the specimens called C. loculosus occurred (vide p. 7I). 


\section{Comparison of the New Specimens with C. Wedekindi, C. Loculosus, ANd C. Robustus, Felix.}

The dimensions of the various parts have been ascertained by my friend, Miss Lockhart, B.Sc., and comparison made with those cited by Felix for his forms. It is found that the leaf decreased in thickness from the parts where division of the bundles was taking place (Figs. 5 and 6 ) to the parts where division seems to have ceased (Fig. 10).

The thickness also decreased from the centre to the periphery. The margin of the leaf for about a width of 2 millimetres was not more than I $\mu$ in thickness. From the data available the whole width cannot have been less than $\mathrm{I} 6 \mathrm{~mm}$.- - possibly more, but no complete transverse sections are available. The thickness ranges from $19 \mu$ to $88 \mu$, but Felix reports for C. Wedekindi a range from 82 to $99 \mu$. The space intervening between the partitions ranges from $47 \mu$ to $60 \mu$, whereas Felix reports a range from 55 to $66 \mu$. The partitions are seldom less than three fibres in width and often show five even in the upper parts of the leaf (Fig. IO, $P a$ ).

In $C$. Wedekindi, on the other hand, even where division of the bundle is still taking place, the partitions are shown to be comparatively thin. ${ }^{1}$

The bundle sheath in the new species is also relatively better developed than in $C$. Wedekindi.

In $C$. Felicis the leaf parenchyma is built up of transversely running strands of cells which are slightly elongated in the direction at right angles to the bundles. These strands show very narrow crevices between them which are exaggerated by the shrinkage of the cells in Fig. 3. The lacunae do not show in transverse sections of the leaf, as the sections are thicker than the cells or the lacunae. They can be detected with difficulty in longitudinal sections taken vertically to the surface between the bundles (Fig. 4), but are always clearly seen in horizontal sections (Fig. 3).

No crystals have been observed, though the cells occasionally show blackened contents-a state of preservation which appears to correspond in the bundle sheath with an incomplete differentiation of the fibre.

Thus $C$. Felicis appears to be a leaf of relatively robuster build than C. Wedekindi. It has a much wider range of structure than was attributed to $C$. Wedekindi by Felix - the term being used to include forms which somewhat resemble $C$. loculosus and $C$. robustus, Felix. The latter, however, like the ' $W$ edekindi' form, exceed the basal sections of $C$. Felicis in size, for the section of ' $C$. robustus' described reaches a thickness of II $5 \mu$ as compared with the $75 \mu$ reached by a section of $C$. Felicis in what I regard as a corresponding plane (Fig. 5).

\footnotetext{
${ }^{1}$ Felix: loc. cit., Pl. III, Fig. 4 (the only published figure of this species).
} 


\section{Comparison of C. FElicis with Renault's Species, \\ 'C. PRINCIPALIS', ETC.}

Renault describes and figures six forms under the specific names C. tenuistriatus, C. angulosostriatus, C. rhombinervis, C. crassus, C. lingulatus, and $C$. principalis. The two last-named species have been further examined by Dr. M. C. Stopes. ${ }^{1}$ These forms all differ from C. Wedekindi, Felix, and from the new species in having only incomplete partitions between the bundles. The horizontally extended strands of cells of the leaf parenchyma are thus continuous from one bundle to the next in the median horizontal plane of the leaf. Three of the species-C. rhombinervis, C. lingulatus, and C. tenuistriatus - show much better differentiated palisade than occurs in $C$. Wedekindi or C. Felicis.

The use of the specific term 'Felicis' for the new species seems therefore doubly appropriate, as it is obviously much more nearly related to the species described by Prof. Felix than to any other described species, and possibly both may have to be placed in a new genus when attribution to their parent plants is possible.

That such an end may be achieved in the near future is rendered more probable by the announcement of a new genus of Cordaitales on stem characters by Messrs. Scott and Maslen in I9IO. ${ }^{2}$ It may also be worth while to put on record that at least ten specimens of the supposed Cordaitean seed Mitrospermum compressum, Will., ${ }^{3}$ occurred in close association with the specimens of the Cordaitean leaf described and figured in this paper.

\section{Diagnosis of CoRdaites Felicis, SP. NOv.}

Leaf of the general Cordaitean type with numerous parallel collateral bundles. Each bundle is surrounded with a well-developed sheath except in the thicker, presumably basal, part of the leaf.

Alternating with the bundles are complete fibrous partitions also disposed longitudinally.

The centripetal elements of the mesarch xylem are better developed than the centrifugal, and consist of two or more tracheides with porose marking. The centrifugal xylem is more abundant in the thicker parts of the leaf and is shown best in the region, presumably basal, where the bundles are dividing. Elements similar to the centrifugal wood partially line the abaxial part of the bundle sheath, and it is suggested they may

1 Renault : Cours de Botanique fossile, pp. 90-3; with Pl. XII, Stopes : loc. cit.

2 Dr. D. H. Scott and Maslen : Preliminary Note, On Mesoxylon, a new genus of Cordaitales. Annals of Botany, vol. xxiv, I910, p. 236.

${ }^{3}$ Dr. Agnes Arber: On the structure of the Palaeozoic Seed Mitrospermum compressum, Will. Annals of Botany, vol. xxiv, igro, p. 491. 
represent an incipient phase in the formation of primary transfusion tissue. The palisade is but little differentiated, and the leaf parenchyma is but slightly lacunar even on the abaxial surface of the leaf, which is stomatiferous except at the base.

The whole leaf has a markedly xerophilous character, and shows in its upper part a considerable resemblance to the type named $C$. Wedekindi by Felix, while in the basal parts it more resembles the types called $C$. loculosus and $C$. robustus by the same author.

\section{EXPLANATION OF PLATE XXII.}

\section{Illustrating Dr. Margaret Benson's paper on Cordaites Felicis.}

The following abbreviations are used: $-H=$ hypodermal strand of fibres between bundle and partition; $I s=$ inner and $O s=$ outer sheath of bundle ; $L=$ lacunae of leaf $P=$ phloem; $P a=$ partition ; $x=$ centrifugal xylem. $x^{\prime}=$ centripetal xylem.

All the slides come from the R. H. C. Collection. The micrographs, with the exception of Fig. I I, were taken and the sections cut by C. H. Wells, the Botanical Laboratory attendant.

Fig. I. Transverse section, probably in the upper part of the lamina, under a low magnification to show distribution of bundles and sclerenchyma. C. N., 365. I. $\times 20$.

Fig. 2. Transverse section, probably in the basal part of the lamina, under a low magnification to show distinctive character. C. N., $3^{6} 5.2$. $\times 20$.

Fig. 3. Horizontal longitudinal section in the upper part of the lamina. The plane of section is about equidistant from each surface. The cells of the leaf parenchyma are collapsed and the lacunae between the strands are therefore exaggerated. C. N., 368. $2 . \times 20$.

Fig. 4. Longitudinal section vertical to the surfaces in plane between the bundle and the partition. The minute size of the lacunae is shown well. The palisade is to the right of the figure. C. N., $3^{65}$. 10. $\times 95$.

Fig. 5. Transverse section in thicker part, to show weak development of bundle sheath and corresponding increase in strength of partition. This figure should be compared with the low-power photograph shown in Fig. 2, and with Felix's figure of C. robustus, to which reference is made in the text. C. N., $3^{6} 5.8 . \times 95$.

Fig. 6. A single bundle from a section in the basal part of the leaf. There is much centrifugal wood and division of the bundle is proceeding. C. N., $3^{65}$. I9. $\times 95$.

Fig. 7. Transverse section through a somewhat thicker part of a leaf, showing both centrifugal xylem and inner sheath. The compact nature of the leaf parenchyma is shown. C. N., $36_{5}$. $12 . \times 95$.

Fig. 8. Transverse section of a bundle in the upper part of the leaf, showing inner sheath but otherwise no centrifugal xylem. C. N., 365. 3. $\times 95$.

Fig. 9. A transverse section showing incipient division of a bundle which sometimes occurs in the middle portion of the lamina. Divisions in this plane are carried out in bundles which have a normal sheath. C. N., 365. 4. $\times 95$.

Fig. I0. Transverse section showing inner sheath and phloem. The hypodermal mass $(H)$ intervening between the partitions $(P a)$ and the bundle strand is indicated; also the position of stomates is indicated on either side of the bundle strand. C. N., $36_{5} .5 . \quad \times 95$.

Fig. II. Photograph of transverse section from the same leaf as the text-figure is taken from. $P=$ phloem, $x=$ centrifugal xylem, and $I s=$ inner sheath. C. N., 72. I. $\times 225$. 
Atronats of Botany,

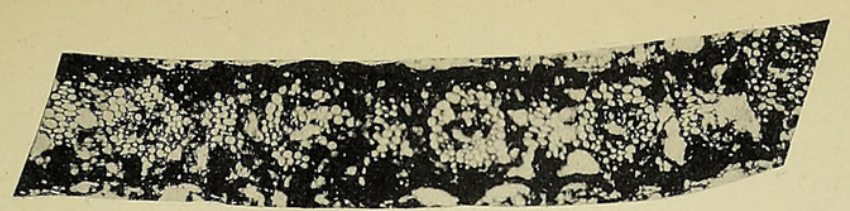

$$
1 .
$$

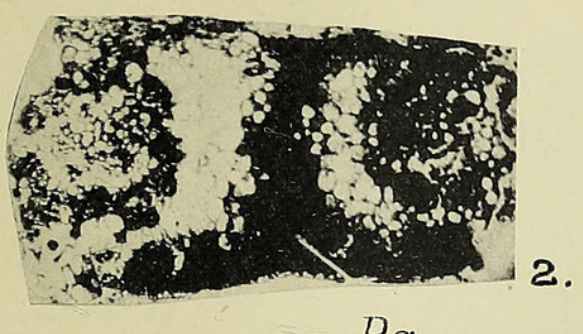

$$
P \alpha \text {. }
$$

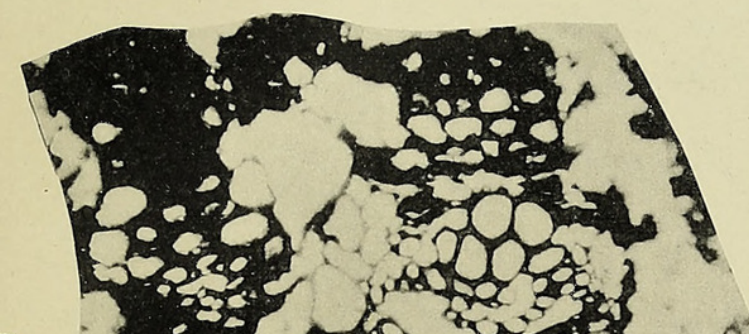

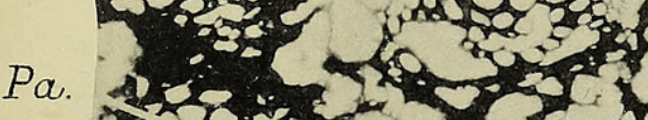

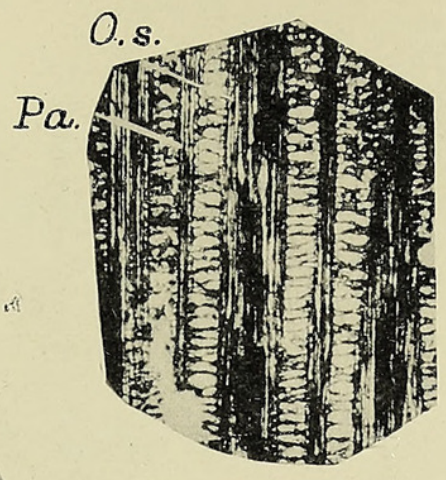

3.

Vol.XXVI, Pl.XXII.
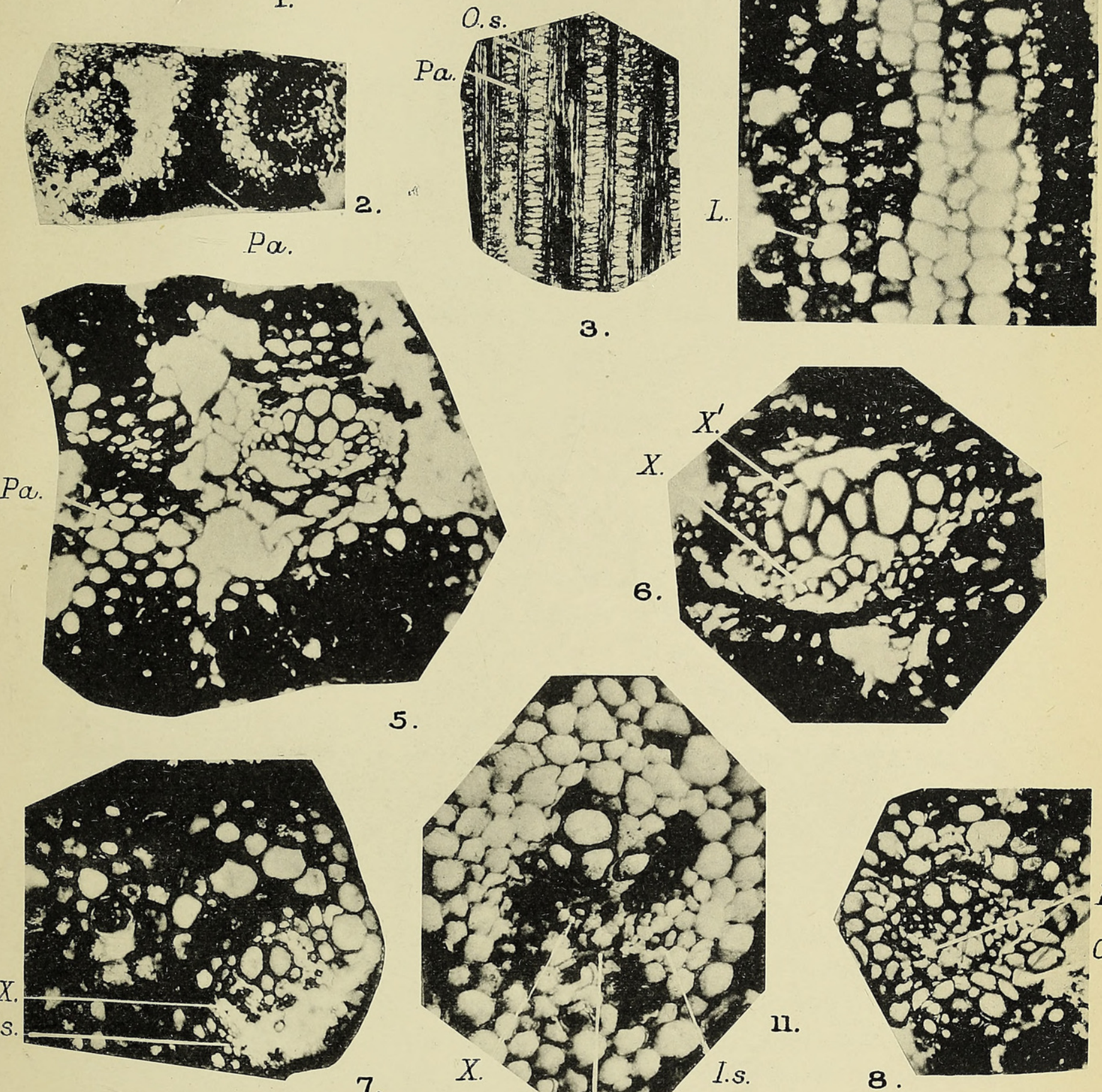

4. $3 x \ln (2) \div$

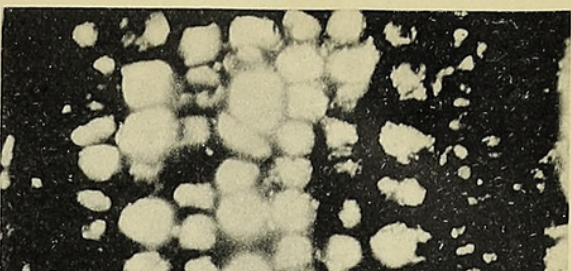

6.
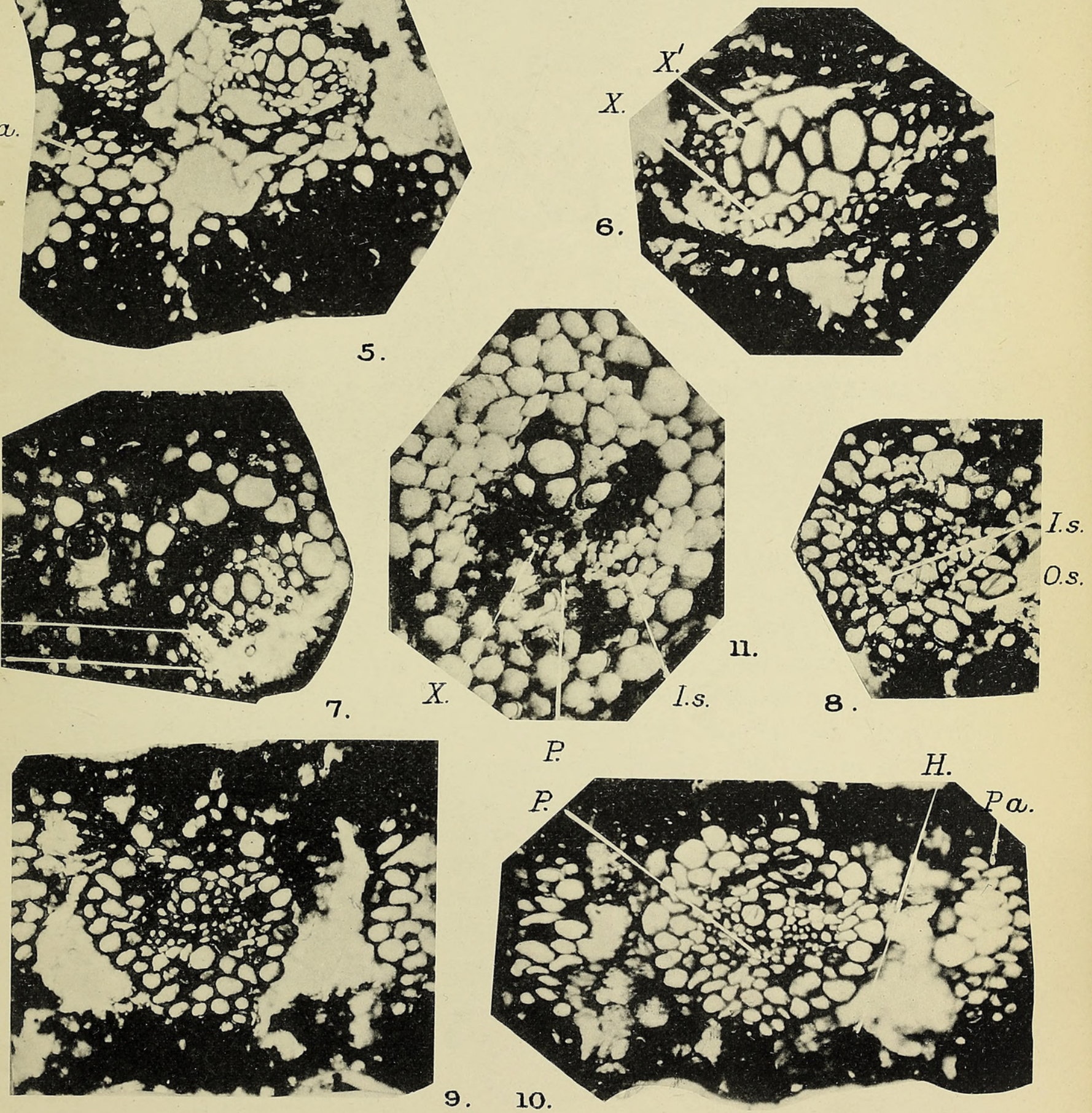

9. 10.

11.

8 


\section{$2 \mathrm{BHL}$ Biodiversity Heritage Library}

Benson, Margaret. 1912. "Cordaites felicis, sp. nov., a cordaitean leaf from the lower coal measures of England." Annals of botany 26, 201-207. https://doi.org/10.1093/oxfordjournals.aob.a089385.

View This Item Online: https://www.biodiversitylibrary.org/item/236773

DOI: https://doi.org/10.1093/oxfordjournals.aob.a089385

Permalink: https://www.biodiversitylibrary.org/partpdf/319902

\section{Holding Institution}

Smithsonian Libraries

\section{Sponsored by}

Biodiversity Heritage Library

\section{Copyright \& Reuse}

Copyright Status: Not in copyright. The BHL knows of no copyright restrictions on this item.

This document was created from content at the Biodiversity Heritage Library, the world's largest open access digital library for biodiversity literature and archives. Visit BHL at https://www.biodiversitylibrary.org. 